\title{
Layout of Urban Distribution Center Using Possibilistic Programming
}

\author{
Nurgul Demirtas ${ }^{1}$, Umut R. Tuzkaya ${ }^{2}$, Mehmet Tanyaş ${ }^{3}$ \\ ${ }^{1}$ Istanbul, Turkey \\ E-mail: nurguldemirtas@gmail.com \\ ${ }^{2}$ Department of Industrial Engineering, Yildiz Technical University, \\ Barbaros St. Yildiz, Besiktas \\ Istanbul, 34349, Turkey \\ E-mail: tuzkaya@yildiz.edu.tr \\ ${ }^{3}$ Department of International Trade and Logistics Management, Maltepe University, \\ Marmara Education Village, Maltepe, \\ Istanbul, 34857, Turkey \\ E-mail: mehmettanyas@maltepe.edu.tr
}

Received 17 January 2016

Accepted 22 June 2016

\begin{abstract}
Distribution centers, link supply chain to the customers. Layout of the distribution centers is very important in terms of product conservation at the required service level and delivering of products with minimum cost to the customer from distribution centers. Therefore, the layout design of distribution centers should be handled with a smart decision system. In this study, the layout design of a fruits and vegetable hall, which is a kind of urban distribution center, is investigated for two different scenarios: (1) assignments of the brokers to the stores and (2) assignments of the products to the stores. The study suggests the most suitable allocation models for the inner layout of distribution center. In the first phase, the requirements of the mathematical model to develop the decision making system for the layouts of distribution center that will be determined. In the second phase, allocation models will be developed and solved for fruits and vegetables halls in Istanbul.
\end{abstract}

Keywords: City Logistics, Fruits and Vegetables Hall, Warehouse Design, Possibilictic Linear Programming, Linear Programming

\section{Introduction}

Survival of corporations, in the global market, is related with providing of dynamic market demands with the minimal cost and on time by effective supply chain management. Providing of market demands with the minimums cost and within the on time are important for the corporations. And also, they hopes increase their profitability and efficiency. Increasing competition forces the companies to create more effective supply chains basing on management and engineering. ${ }^{1}$
A typical supply chain consists of multiple agents, such as suppliers, production facilities, warehouses, distribution centers and points of sales. Especially distribution center is one of the most important rings in terms of providing on time delivery, minimum cost and expected service quality. Besides, the layout of the distribution centers is very important for storage of the goods and distribution to the customers with a high service quality.

Distribution centers occupy an important position in the supply chain; such centers store products, and retrieve products from storage to fulfill customer orders. 
Warehousing is the essence of the businesses for companies such as wholesale distributors. Since warehousing activities are intensive, even small improvements can achieve significant savings. One costly way of increasing the warehousing productivity is through novel distribution center design. It is also possible to increase the productivity by less radical methods including changing the warehousing activities, such as receiving, order picking and shipping. ${ }^{2}$

In the past decade, researches show us there has been increasing attention to provide better services with minimum cost using distribution center (DC).

Researches on examining the DC in the literature are explained below.

Chen et al. $^{2}$ studied on the problem of constructing order batches for distribution centers using a data mining technique. Xing et $\mathrm{al}^{3}$ studied on the location adjustment model of the store area in distribution center. Avittathur et al. $^{4}$ developed a model for determining DCs' locations considering the impact of the central sales tax. Yang et al. ${ }^{5}$ investigated the logistics distribution centers location problem under fuzzy environment from another point of view, in which setup cost, turnover cost and demand of each customer are supposed to be fuzzy variables.

Distribution centers have a vital importance among the supply chain network and their layouts come into prominence for transporting the goods to customers with minimum total cost and time. While constructing a distribution center facility, sophisticated plans should be consider to assure comprehensive and long term strategies. Tanyas ${ }^{6}$ explains issues for the layout planning of the distribution center as follows:

- Handling, storage, packaging and other logistic activities that includes value added services should be considered in the layout planning.

- Usage time of vehicles from receiving to delivery should be minimized in distribution centers.

- The products should be delivered to customers with minimum transportation and handling operations.

- The products should be located according to the their characteristics

- Investment costs like building, plumbing, equipment, etc. should be minimized.

- Labor, energy, and operating costs etc. should be minimized.

- Support services such as safety, cleaning, auxiliary materials, accommodation etc. should be provided at lowest cost.
- The layout should be flexible considering expansion possibilities. ${ }^{6}$

Distribution center layout, which is a specific type of facility design problem, is constituted by assigning products or brokers to predetermined locations efficiently. However, this assignment problem includes many external affects, especially in distribution centers located in cities, which are named as urban distribution centers. For instance, irregular layout affects the urban traffic directly with truck and pickup queues at the neighborhood of urban distribution center. A typical example of urban distribution centers is Fruits and Vegetable Wholesale Market Hall (F\&VM).

The layout of a F\&VM is related with sponsors and founders of the hall, retailers, wholesalers, truck drivers and pickup drivers. Truck and pickup drivers want to decrease the total duration between entrance and leaving span in the F\&VM and retailers want to see more exhibits of the wholesalers in a short time. Since the most of the products are perishable and delicate in F\&VMs, their handling operations should be minimized to not damage them. Besides, the environmental effects on the products should be considered throughout the process. Local governments, sponsors and founders of the hall are interested in the low investment cost which includes building, materials and equipment to be used, while fulfilling the requirements of the users. The operating and supporting costs should also be minimized while providing a contemporary working environment. Although the expanding opportunities of a hall are mostly related with the location selection decisions and neighborhood of it, layout also should be designed considering these future necessities.

In addition to the above-mentioned stakeholders who are directly affected from the layout of F\&VM, city residents can be affected badly due to the high-density traffic, visual pollution, environmental pollution etc. A F\&VM layout with inadequate designed parking areas, storage areas, cold storage warehouses, supporting facilities, loading/unloading platforms and docks causes truck and pickup queues in front of the hall docks or environmental pollution due to the rotten products and wastes. As a result, objectives and constraints mentioned above should be considered in the design phase of a hall. Determining the relative locations and the sizes of warehouses and the exhibition areas is very important. Relations of the products, which can be affected from each other, should be considered while 
calculating the indoor and outdoor requirements. Also by using statistical data, retailers, who are the customers of the F\&VMs, may be classified to the groups with respect to the product group that they intended to buy. Thus, a cellular layout can be designed by providing the aim of short walking time for the retailers in the hall. ${ }^{7}$ In this study, we established a decision support system for layout decision of an urban distribution center. The methodology used for $\mathrm{F} \& \mathrm{VM}$ is developed for allocation of products and brokers to the warehouses and exhibition areas.

\section{Possibilistic Linear Programming}

In this study, we use Possibilistic Linear Programming (PLP) methodology to solve the proposed mathematical models. Some example studies in the literature related the PLP are explained below.

Assadipour and $\mathrm{Razmi}^{8}$ investigated the problem of inventory lot-sizing and supplier selection for an assembly system where the supplier available capacities are assumed as ambiguous dynamic parameters. In study a particle swarm optimization was used to achieve the overall satisfactory compromise solution.

Vahdani et $\mathrm{al}^{9}$ focused on a logistics network which includes multi-suppliers, collection centers, transfer stations, treatment stations, and products. They proposed a multi-objective mathematical programming model that minimizes the total costs including the fixed costs for opening facilities and transportation costs between facilities; minimizes the distance between each waste-generating facilities and transfer stations; maximizes the distance between treatment and disposal stations and customer zones; and maximizes the sum of the reliability of coverage for the potential facilities which will be open by combining fuzzy possibilistic programming, stochastic programming, and fuzzy multi-objective programming.

Bouzembrak et $\mathrm{al}^{10}$ developed develop a possibilistic linear programming model for supply chain network design with imprecise inputs: market demands, supplied quantities, transportation costs, opening costs, treatment and storage costs are modelled as fuzzy numbers.

Ozgen and Gulsun ${ }^{11}$ studied on a two-phase possibilistic linear programming approach and a fuzzy analytical hierarchical process approach. They combined those approaches to optimize two objective functions ("minimum cost" and "maximum qualitative factors benefit') in a four-stage (suppliers, plants, distribution centers, customers) supply chain network in the presence of vagueness.

Niakan and Rahami ${ }^{12}$ studied on a new multi-objective mathematical model to address a Healthcare Inventory Routing Problem for medicinal drug distribution to healthcare facilities. They applied a hybridized possibilistic method to cope with uncertainty. And an interactive fuzzy approach was considered to solve an auxiliary crisp multi-objective model and find optimized solutions

Tofighi et $\mathrm{al}^{13}$ studied on a two-echelon humanitarian logistics network design problem involving multiplecentral warehouses and local distribution centers. They developed a novel two-stage scenario-based possibilistic-stochastic programming approach.

Dai et $\mathrm{al}^{14}$ developed an interval-fuzzy possibilistic programming (IFPP) method by integrating interval parameter programming (IPP), fuzzy possibilistic programming (FPP), and a fuzzy expected value equation within a general optimization framework.

An ambiguous datum is represented by a possibility distribution $\pi_{\mathrm{ij}}$ in PLP. A possibility distribution $\pi_{\mathrm{ij}}$ is defined by a fuzzy set with $A_{i j}$ representing a linguistic expression such as "about $a_{i j}$ " as $\pi_{i j}=\mu_{A_{i j}}$, where $\mu_{\mathrm{A}_{\mathrm{ij}}}$ is a membership function of $\mathrm{A}_{\mathrm{ij}}$. A variable $\alpha_{\mathrm{ij}}$, restricted by a possibility distribution $\pi_{\mathrm{ij}}$, is called a possibilistic variable. Zadeh ${ }^{15}$ studied on the generalized constraints related with the uncertainty situations as possibilistic, probabilistic, and heuristic constraints. In the possibilistic programming approach, a vague aspiration is represented by a fuzzy goal $G_{i}$. A possibilistic linear programming (PLP) problem with imprecise fuzzy coefficients can be stated as

$\max \sum_{\mathrm{i}=1}^{\mathrm{n}} \widetilde{\mathrm{c}_{1}} \mathrm{x}_{\mathrm{i}}$

s.t. $\mathrm{x} \in \mathrm{X}=\{\mathrm{xIAx} \leq \widetilde{\mathrm{b}}$ and $\mathrm{x} \geq 0\}$

where $\widetilde{c_{1}}:\left(c_{i}^{p}, c_{i}^{m}, c_{i}^{0}\right)$ for all $i$, are imprecise fuzzy coefficients and have triangular possibility distributions. In this study, the triangular fuzzy numbers are used but on the other hand trapezoidal numbers can be used to on PLP. Real world problems usually involve uncertain data, decision makers should handle this imprecise or fuzzy environment. Hence, the possibility distributions estimated by the decision makers can be described more simply by triangular fuzzy numbers. The most possible value is $c_{\mathrm{i}}^{\mathrm{m}}$ (possibility $=1$, if normalized); $c_{i}^{p}$ (the most pessimistic value) and $c_{i}^{o}$ (the 
most optimistic value) are the least possible values. The possibility distributions $\left(\pi_{i}\right)$ can be expressed as the degree of occurrence of an event.

The imprecise objective function with a triangular possibility distribution can be written as

$\max \left(\left(c_{i}^{\mathrm{m}}\right)^{\mathrm{T}},\left(c_{i}^{\mathrm{p}}\right)^{\mathrm{T}},\left(c_{i}^{\mathrm{o}}\right)^{\mathrm{T}}\right)$

The auxiliary multi objective problem for solving Eq.

(2) can be formulated as follows

$\min \mathrm{z}_{1}=\left(c^{\mathrm{m}}-\mathrm{c}^{\mathrm{p}}\right)^{\mathrm{T}} \mathrm{x}$

$\max \mathrm{z}_{2}=\left(\mathrm{c}^{\mathrm{m}}\right)^{\mathrm{T}} \mathrm{x}$

$\min z_{3}=\left(c^{o}-c^{m}\right)^{T} x$

s.t. $x \in X$

In PLP methodology, the multi-objective programming problem can be solved using the concept of fuzzy set developed by Zimmerman (1978).

$\max \mathrm{Z}=\left[\mathrm{c}_{1} \mathrm{x}, \mathrm{c}_{2} \mathrm{x}, \ldots \mathrm{c}_{\mathrm{i}} \mathrm{x}\right]^{\mathrm{T}}$

$\min W=\left[c_{1} x, c_{2} x, \ldots c_{i} x\right]^{T}$

s.t.

$\mathrm{Ax} \leq \mathrm{b}$

$\mathrm{x} \geq 0$

The membership functions of the objective are formulated as

$\mu_{k}\left(Z_{k}\right)=\frac{Z_{k}(x)-Z_{k}^{N I S}}{Z_{k}^{P I S}-Z_{k}^{N I S}}, \quad k=1,2, \ldots, l$

$\mu_{\mathrm{k}}\left(\mathrm{W}_{\mathrm{s}}\right)=\frac{\mathrm{W}_{\mathrm{S}}^{\mathrm{NIS}}-\mathrm{W}_{\mathrm{s}}(\mathrm{x})}{\mathrm{W}_{\mathrm{s}}^{\mathrm{NIS}}-\mathrm{W}_{\mathrm{s}}^{\mathrm{PIS}}}, \mathrm{s}=1,2, \ldots, \mathrm{r}$

$\mathrm{Zk}(\mathrm{x})$ and $\mathrm{Ws}(\mathrm{x})$ are minimization and maximization objective function. $\mathrm{Z}_{\mathrm{k}}^{\mathrm{PIS}}, \mathrm{W}_{\mathrm{s}}^{\mathrm{PIS}}$ and $\mathrm{Z}_{\mathrm{k}}^{\mathrm{NIS}}, \mathrm{W}_{\mathrm{s}}^{\mathrm{NIS}}$ is defined as the positive and negative ideal solutions. With the "max-min" operator and $\lambda^{(1)}$ satisfaction degree, the multi objective linear programming problem can be solved as a single objective problem: ${ }^{16}$

$\max \lambda^{(1)}$

s.t.

$\lambda^{(1)} \leq\left(\mathrm{Z}_{\mathrm{k}}(\mathrm{x})-\mathrm{Z}_{\mathrm{k}}^{\mathrm{NIS}}\right) /\left(\mathrm{Z}_{\mathrm{k}}^{\mathrm{PIS}}-\mathrm{Z}_{\mathrm{k}}^{\mathrm{NIS}}\right), \mathrm{k}=1,2 \ldots \mathrm{l}$

$\lambda^{(1)} \leq\left(\mathrm{W}_{\mathrm{s}}^{\mathrm{NIS}}-\mathrm{W}_{\mathrm{s}}(\mathrm{x})\right) /\left(\mathrm{W}_{\mathrm{s}}^{\mathrm{NIS}}-\mathrm{W}_{\mathrm{S}}^{\mathrm{PIS}}\right), \mathrm{s}=1,2 . . \mathrm{r}$

$\mathrm{x} \in \mathrm{X}$

$\lambda \in[0,1]$

\section{Layout Design Model of Warehouse And Exhibition Area in F\&VM}

The objective of this study is to minimize the summation of (1) vehicle loading-unloading time, (2) transportation time of the products from dock to the warehouse locations, and (3) customer's walking time in the exhibition area of the F\&VM. The mathematical model constituted to obtain a decision making system while designing a layout of F\&VM. Two different layouts of distribution centers are investigated and two mathematical models are proposed for the "distribution center layout with an exhibition area and a single warehouse".

The layout of urban distribution center is an important factor on navigation of the customers and movements of the products. These movements include unloading of the products from larger vehicle, loading them to the customers' vehicle, and delivering them to the end user as soon as possible. Therefore, the layout design of a $\mathrm{F} \& \mathrm{VM}$ is more important than the architectural and esthetical aspects. While designing hall layout alternatives, integrated logistics activities should be taken into account such as, transportation, warehousing, packing, and value added services etc. ${ }^{7}$

Before this study, Tanyas et al. ${ }^{7}$ applied "Distribution center layout with an exhibition area and a single warehouse" for the Tuzla-Aydınlı F\&VM in Istanbul, Turkey using Fuzzy Axiomatic Design, which is a multi-criteria decision-making technique. It was determined that the uncertainty of some data should be used in the creation of appropriate decision support systems.

As a result of discussions with experts, the minimization of the total navigation time of customers, long vehicles and trucks in the hall are main performance criteria for the layout of F\&VM. The accepted structure of the layout consists of two separate parts: the exhibition areas where small part of fruits and vegetables are exhibited and the warehouse building where the all remaining products are stored. Each long vehicle parks at the specific area reserved for them near the warehouses, and products are transferred to warehouses by forklifts. On the other hand, customers walk around the exhibition areas for buying fruits and vegetables and then load products to their vehicles by forklifts. Customers park their small vehicles to parking areas reserved for them. 
Considering these situations, we proposed two alternative warehouse layouts: (1) product based warehouse design and (2) broker based warehouse design. Since the customers' total walking time in exhibition area and the handling operations in the warehouse do not affect each other, we figured out the problems as two separate models. As a result, three models are applied for three problem separately: (1) exhibition area design problem, (2) product based warehouse design and (3) broker based warehouse design.

The used data related with the amount of products delivering to each brokers, distances between points of loading-unloading areas and reserved warehouse, and distances between starting point and exhibition areas are given as fuzzy $(\sim)$ parameters. Therefore, to represent this fuzziness in the solution process, problems are modeled with Possibilistic Linear Programming (PLP) methodology. Notations used in the models are given below.

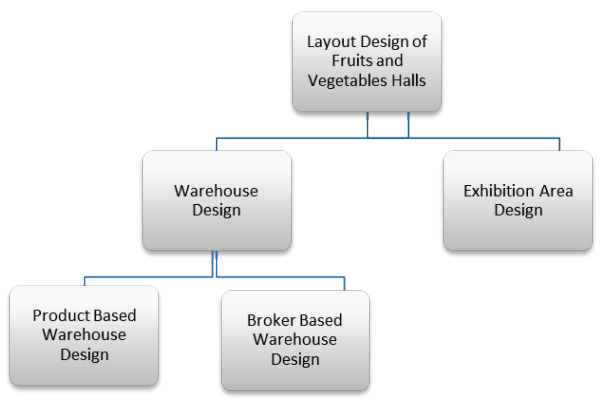

Fig. 1. The alternative layout design for distribution center $x_{i l}: 1$ if broker $i$ is assigned to exhibiton area $l$ , 0 otherwise

$y_{i k}: 1$ if broker $i$ is assigned to reserved warehouse area $k, 0$ otherwise

$y_{j k}: 1$ if product $j$ is assigned to reserved warehouse area $k$

\section{$\underline{\text { Parameters }}$}

$\widetilde{c_{l}}:$ Number of customers who walk around broker $i$

$\widetilde{d}_{l}:$ The distance from the starting point to the exhibition area $l(m)$

$\widetilde{d_{k}^{b}}:$ The distance from the unloading point of products to reserved warehouse area $k(m)$

$\widetilde{d_{k}^{y}}:$ The distance from reserved warehouse area $k$ to the product loading point $(m)$ $\widetilde{m_{l}}$ : The amount of product $j$ comes to broker $i(\mathrm{~kg})$ $f c_{j}$ :The capacity of forklift which is used to transfer the product $j$ from unloading $f s j$ point of products $(\mathrm{kg} /$ forklift $)$

:The speed of forklift which is used to move product $j\left(\frac{m}{\text { minute }}\right)$ ws : Average human walking speed ( $\mathrm{m} /$ minute)

$C P_{k}:$ Maximum capacity of warehouse $k(\mathrm{~m} 3)$ vj: The volume of one unit of the product $j(\mathrm{~m} 3)$

\section{$\underline{\text { Index }}$}

$$
\begin{aligned}
& i \text { : set of brokers } \quad i=1,2, \ldots, I \\
& j: \text { set of product types } \quad j=1,2, \ldots, J \\
& k \text { : set of reserved warehouse areas } \\
& \quad k=1,2, \ldots, K \\
& l \text { : set of exhibition areas } l=1,2, \ldots, L
\end{aligned}
$$

\section{Decision Variables}

$x_{i j k}$ : The amount of product $j$ assigned to reserved warehouse area $k$ for broker $i(\mathrm{~kg})$ 


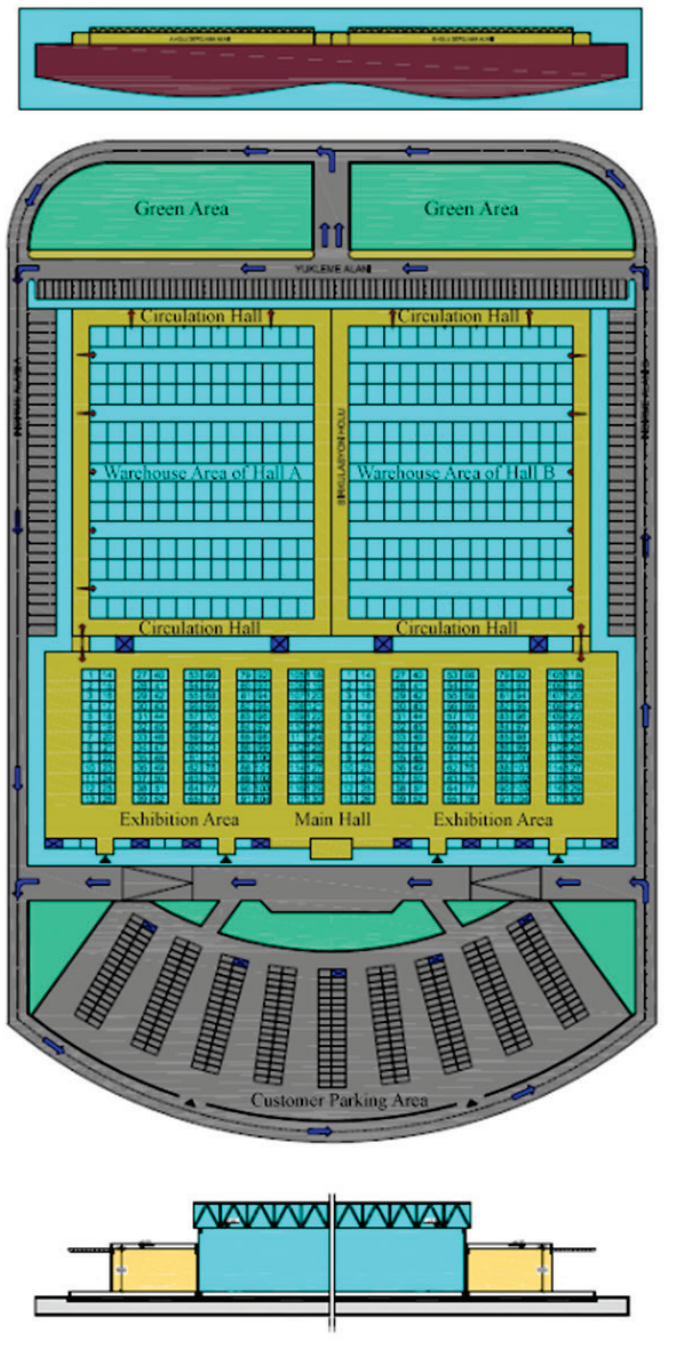

Fig. 2. Distribution center layout with an exhibition area and a single warehouse

\subsection{Exhibition area design $\left(A_{1}\right)$}

Mathematical model for designing the layout of the exhibition area, which is used for the appointment of brokers (tenants) and customers, is presented below. The entry points to exhibition area and the counts of customers walking around are given as fuzzified parameters in the model.

$\min \mathrm{z}=\sum_{\mathrm{i}} \sum_{1} \mathrm{x}_{\mathrm{il}} \widetilde{\mathrm{c}}_{\mathrm{i}} \tilde{\mathrm{t}}_{\mathrm{l}}$

s.t.

$\sum_{l} x_{i l}=1 \quad \forall i$ $\sum_{i} x_{i l}=1 \quad \forall l$

$\tilde{\mathrm{t}}_{1}=\frac{\tilde{\mathrm{d}}_{1}}{\mathrm{ws}}$

$\mathrm{x}_{\mathrm{il}} \in\{0,1\}$

The aim of objective function of $\mathrm{A}_{1}$ model is minimization of the total navigation time of customers in exhibition area. Eq 9 describes navigation time between the starting point and the exhibition area $1 . \mathrm{Eq}$ 10 provides that each broker i can be assigned to only one exhibition area. Eq 11 ensures that exhition area 1 can be assigned to only one broker i. Eq 12 describes navigation time between the starting point and the exhibition area 1. Eq 13 examines the values of decision variables.

$\mathrm{c}_{\mathrm{i}}^{\mathrm{p}}$ and $\mathrm{d}_{1}^{\mathrm{p}}$ are the most pessimistic values and have very low probability of belonging to the set of available values.

$\mathrm{c}_{\mathrm{i}}^{\mathrm{m}}$ and $\mathrm{d}_{1}^{\mathrm{m}}$ are the most possible values and definitely belong to the set of available values. $\mathrm{c}_{\mathrm{i}}{ }^{\mathrm{o}}$ and $\mathrm{d}_{1}{ }^{\mathrm{o}}$ are the most optimistic values and have a very low probability of belonging to the set of available values. Figure presents these triangular possibility distributions.

The possibilistic objective functions that contain coefficients with triangular possibility distributions can

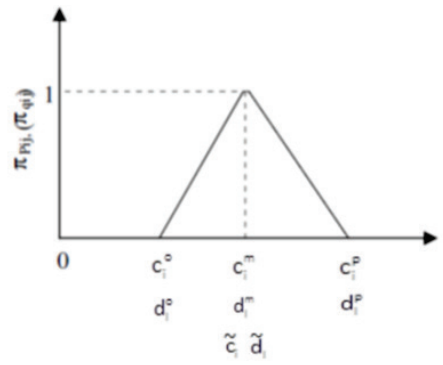

Fig. 3. Triangular possibility distributions for $\widetilde{\mathrm{c}}_{\mathrm{i}}$ and $\tilde{\mathrm{d}}_{1}$

be minimized by pushing $c c_{i}^{o}, c c_{i}^{m}, c c_{i}^{p}$ and $d_{1}^{o}, d_{1}^{m}, d_{1}^{p}$ to the left horizontally.

Lai and Hwang ${ }^{17}$ approach, it is better to minimize $\mathrm{z}^{\mathrm{m}}$, maximize $z^{m}-z^{o}$,mininize $z^{p}-z^{m}$ together. According to, Lai and Hwang's(1992) approach, it is better to minimize $\mathrm{z}^{\mathrm{m}}$, maximize $\mathrm{z}^{\mathrm{m}}-\mathrm{z}^{\mathrm{o}}$, mininize $\mathrm{z}^{\mathrm{p}}-$ $\mathrm{z}^{\mathrm{m}}$ concurently. 
The imprecise objective function, where $\widetilde{C_{l}}=$ $\left(c c_{i}^{o}, c c_{i}^{m}, c c_{i}^{p}\right)$, is formulated as follows:

$$
\begin{aligned}
& \min z_{1}=z^{m}=\sum_{i} \sum_{1} x_{i l} c_{i}^{m} \frac{d_{1}^{m}}{w s} \\
& \max z_{2}=z^{m}-z^{o}=\sum_{i} \sum_{1} x_{i l}\left(c_{i}^{m} \quad c_{i}^{o}\right) \frac{\left(d_{1}^{m} \quad d_{1}^{o}\right)}{w s} \\
& \min x z_{3}=z^{p}-z^{m}=\sum_{i} \sum_{1} x_{i l}\left(c_{i}^{p} \quad c_{i}^{m}\right) \frac{\left(d_{1}^{p} \quad d_{1}^{m}\right)}{w s}
\end{aligned}
$$

s.t.

$\sum_{l} x_{i l}=1 \quad \forall i$

$\sum_{i} x_{i l}=1 \quad \forall l$

$x_{i l} \in\{0,1\}$

Under these constraints, the objective function tries to minimize the total customers rounding time in the exhibition areas.

\subsection{Warehouse Design}

\subsubsection{Broker Based Warehouse Design $\left(A_{21}\right)$}

Broker based warehouse design includes assignment process of each broker to determined warehouse areas. Exhibiton area is placed aside of the warehouse seperately, as well as product based warehouse design. The loading and unloading points, where vehicles are parked, are given in fuzzified form for the considered period.

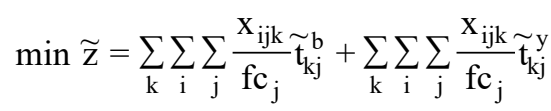

s.t.

$\sum_{k} x_{i j k}=\tilde{m}_{i j} \quad \forall i, j$

$\sum_{i} y_{i k} \leq 1 \quad \forall k$

$\sum_{j} x_{i j k} v_{j} \leq y_{i k} C P_{k} \quad \forall i, k$

$\sum_{k} y_{i k} \quad \sum_{k} \sum_{j} x_{i j k} v_{j} / C P_{k} \leq 1 \quad \forall i$

$$
\begin{gathered}
\widetilde{\mathfrak{t}}_{\mathrm{kj}}^{\mathrm{b}}=\frac{\widetilde{\mathrm{d}}_{\mathrm{k}}^{\mathrm{b}}}{\mathrm{fs}_{\mathrm{j}}} \\
\widetilde{\mathfrak{t}}_{\mathrm{kj}}^{\mathrm{y}}=\frac{\widetilde{\mathrm{d}}_{\mathrm{k}}^{\mathrm{y}}}{\mathrm{fs}_{\mathrm{j}}} \\
\mathrm{y}_{\mathrm{ik}} \in\{0,1\} \\
\mathrm{x}_{\mathrm{ijk}} \geq 0
\end{gathered}
$$

The imprecise objective function $\left(\widetilde{\mathrm{d}_{1}}=\left(\mathrm{d}_{1}^{\mathrm{o}}, \mathrm{d}_{1}^{\mathrm{m}}, \mathrm{d}_{1}^{\mathrm{p}}\right)\right)$ is formulated as follows:

$$
\begin{aligned}
& \min \mathrm{z}_{1}=\mathrm{z}^{\mathrm{m}}=\sum_{\mathrm{k}} \sum_{\mathrm{i}} \sum_{\mathrm{j}} \frac{\mathrm{x}_{\mathrm{ijk}}}{\mathrm{fc}_{\mathrm{j}}} \frac{\mathrm{d}_{\mathrm{k}}^{\mathrm{b}^{\mathrm{m}}}}{\mathrm{fs}_{\mathrm{j}}}+\sum_{\mathrm{k}} \sum_{\mathrm{i}} \sum_{\mathrm{j}} \frac{\mathrm{x}_{\mathrm{ijk}}}{\mathrm{fc}_{\mathrm{j}}} \frac{\mathrm{d}_{\mathrm{k}}^{\mathrm{y}^{\mathrm{m}}}}{\mathrm{fs}_{\mathrm{j}}} \\
& \max z_{2}=\left(z^{m} \quad z^{o}\right)=\sum_{k} \sum_{i} \sum_{j} \frac{x_{i j k}}{f_{j}} \frac{\left(d_{k}^{b^{m}} d_{k}^{b^{\circ}}\right)}{f s_{j}} \\
& +\sum_{\mathrm{k}} \sum_{\mathrm{i}} \sum_{\mathrm{j}} \frac{\mathrm{x}_{\mathrm{ijk}}}{\mathrm{fc}_{\mathrm{j}}} \frac{\left(\mathrm{d}_{\mathrm{k}}^{\mathrm{y}^{\mathrm{m}}} \mathrm{d}_{\mathrm{k}}^{\mathrm{y}^{\mathrm{o}}}\right)}{\mathrm{fs}_{\mathrm{j}}} \\
& \min z_{3}=\left(\begin{array}{ll}
z^{p} & z^{m}
\end{array}\right)=\sum_{k} \sum_{i} \sum_{j} \frac{x_{i j k}}{f c_{j}} \frac{\left(d_{k}^{b^{p}} d_{k}^{b^{m}}\right)}{f s_{j}} \\
& +\sum_{\mathrm{k}} \sum_{\mathrm{i}} \sum_{\mathrm{j}} \frac{\mathrm{x}_{\mathrm{ijk}}}{\mathrm{fc}_{\mathrm{j}}} \frac{\left(\mathrm{d}_{\mathrm{k}}^{\mathrm{y}^{\mathrm{p}}} \mathrm{d}_{\mathrm{k}}^{\mathrm{y}^{\mathrm{m}}}\right)}{\mathrm{fs}_{\mathrm{j}}}
\end{aligned}
$$

s.t.

$\sum_{k} x_{i j k}=w_{1} m_{i j}^{o}+w_{2} m_{i j}^{m}+w_{3} m_{i j}^{p} \quad \forall i, j$

$\sum_{i} y_{i k} \leq 1 \quad \forall k$

$\sum_{j} x_{i j k} v_{j} \leq y_{i k} C P_{k} \quad \forall i, k$

$\sum_{k} y_{i k} \quad \sum_{k} \sum_{j} x_{i j k} v_{j} / C P_{k} \leq 1 \quad \forall i$

$\mathrm{y}_{\mathrm{ik}} \mathrm{E}\{0,1\}$

$\mathrm{x}_{\mathrm{ijk}} \geq 0$

Eq 20 defines objective function of model $\mathrm{A}_{21}$ minimize the total time of loading and unloading of products. The auxiliary multi objective problem for solving Eq 20 is formulated as Eq 29, Eq 30 and Eq 31. Eq 32 provides that whole products comes to brokers have to be assigned to related warehouse area. Eq 33 ensures that each broker i can be assigned to only one warehouse 
area $\mathrm{k}$. Eq 34 ensures that max amount of product $\mathrm{j}$ of broker $\mathrm{i}$ that is assigned to warehouse area $\mathrm{k}$. Eq 35 guaranties not exceeding the capacity constraint. The broker $\mathrm{k}$ can be assigned more than one warehouse depending on the amount of product that comes to the brokers. Therefore, there is a relation between amount of product that comes to brokers and capacity of warehouse. Eq 36 and 37 are about non negativity and binary variables.

\subsubsection{Product Based Warehouse Design $\left(A_{22}\right)$}

Product based warehouse design includes assignment process of products which are grouped according to the rule of same type to the same warehouse area. Exhibition area is placed in another location from warehouse area again as well as product based warehouse design. The loading and unloading points, where vehicles are parked, are given as fuzzified parameters for considered period:

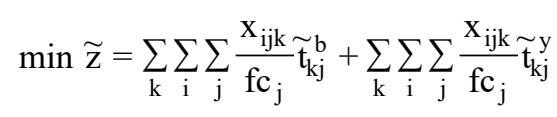

s.t.

$\sum_{k} x_{i j k}=\widetilde{m}_{i j} \quad \forall i, j$

$\sum_{j} y_{j k} \leq 1 \quad \forall k$

$\sum_{i} x_{i j k} v_{j} \leq y_{j k} C P_{k} \quad \forall j, k$

$\sum_{k} y_{j k} \quad \sum_{i} \sum_{k} x_{i j k} v_{j} / C P_{k} \leq 1 \quad \forall j$

$\widetilde{\mathrm{t}}_{\mathrm{kj}}^{\mathrm{b}}=\frac{\widetilde{\mathrm{d}}_{\mathrm{k}}^{\mathrm{b}}}{\mathrm{fs}_{\mathrm{j}}}$

$\widetilde{\mathrm{t}}_{\mathrm{kj}}^{\mathrm{y}}=\frac{\widetilde{\mathrm{d}}_{\mathrm{k}}^{\mathrm{y}}}{\mathrm{fs}_{\mathrm{j}}}$

$\mathrm{y}_{\mathrm{jk}} \in\{0,1\}$

$\mathrm{x}_{\mathrm{ijk}} \geq 0$

The imprecise objective function with a triangular possibility distribution $\left(\widetilde{\mathrm{d}_{1}}=\left(\mathrm{d}_{1}^{\mathrm{o}}, \mathrm{d}_{1}^{\mathrm{m}}, \mathrm{d}_{1}^{\mathrm{p}}\right)\right)$ can be formulated as follows

$$
\begin{aligned}
& \min z_{1}=z^{m}=\sum_{k} \sum_{i} \sum_{j} \frac{x_{i j k}}{f c_{j}} \frac{d_{k}^{b^{m}}}{f s_{j}}+\sum_{k} \sum_{i} \sum_{j} \frac{x_{i j k}}{f c_{j}} \frac{d_{k}^{y^{m}}}{f s_{j}} \\
& \max z_{2}=\left(z^{m} \quad z^{o}\right)=\sum_{k} \sum_{i} \sum_{j} \frac{x_{i j k}}{f_{j}} \frac{\left(d_{k}^{b^{m}} \quad d_{k}^{b^{o}}\right)}{f s_{j}} \\
& +\sum_{\mathrm{k}} \sum_{\mathrm{i}} \sum_{\mathrm{j}} \frac{\mathrm{x}_{\mathrm{ijk}}}{\mathrm{fc}_{\mathrm{j}}} \frac{\left(\mathrm{d}_{\mathrm{k}}^{\mathrm{y}^{\mathrm{m}}} \mathrm{d}_{\mathrm{k}}^{\mathrm{y}^{\mathrm{o}}}\right)}{\mathrm{fs}_{\mathrm{j}}} \\
& \min z_{3}=\left(\begin{array}{ll}
z^{p} & z^{m}
\end{array}\right)=\sum_{k} \sum_{i} \sum_{j} \frac{x_{i j k}}{f c_{j}} \frac{\left(d_{k}^{b^{p}} d_{k}^{b^{m}}\right)}{f s_{j}} \\
& +\sum_{\mathrm{k}} \sum_{\mathrm{i}} \sum_{\mathrm{j}} \frac{\mathrm{x}_{\mathrm{ijk}}}{\mathrm{fc}_{\mathrm{j}}} \frac{\left(\mathrm{d}_{\mathrm{k}}^{\mathrm{y}^{\mathrm{p}}} \mathrm{d}_{\mathrm{k}}^{\mathrm{y}^{\mathrm{m}}}\right)}{\mathrm{fs}_{\mathrm{j}}}
\end{aligned}
$$

s.t.

$\sum_{k} x_{i j k}=w_{1} m_{i j}^{o}+w_{2} m_{i j}^{m}+w_{3} m_{i j}^{p} \quad \forall i, j$

$\sum_{j} y_{j k} \leq 1 \quad \forall k$

$\sum_{i} x_{i j k} v_{j} \leq y_{j k} C P_{k} \quad \forall j, k$

$\sum_{k} y_{j k} \quad \sum_{i} \sum_{k} x_{i j k} v_{j} / C P_{k} \leq 1 \quad \forall j$

$\mathrm{y}_{\mathrm{jk}} \in\{0,1\}$

$\mathrm{x}_{\mathrm{ijk}} \geq 0$

Eq 50 provides that each product $j$ comes to brokers have to be assigned to the related warehouse. Eq 51 ensures that each product type $j$ can be assigned to only one warehouse area $k$. Eq 52 guaranties that amount of product $j$ which is assigned to warehouse area $k$ must be lower than or equal to capacity of warehouse $k$. Eqs 54 and 55 are about non negativity and binary variables.

\section{Case Study}

The models which are developed for distribution centers are used for F\&VMs. All the LP and PLP models are solved by using GAMS program and the results are compared. Each model is solved for small data and large (real world) data. The used data for first step is shown follows: number of brokers are 5, capacity of each warehouse is $595 \mathrm{~m}^{3}$. 


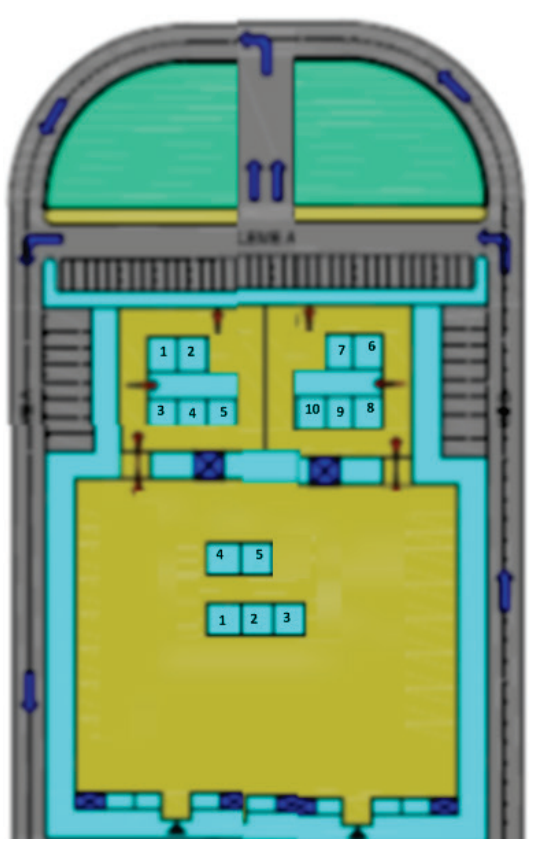

Fig. 4. Distribution center project plan with exhibition area and single warehouse.

The amount of products delivering brokers are shown in Table 1.

Table 1 Amount of Products Delivering Brokers

\begin{tabular}{ccccc}
\hline $\begin{array}{c}\text { Brokers/Product } \\
\text { Type }\end{array}$ & $\mathbf{j}_{\mathbf{1}}$ & $\mathbf{j}_{\mathbf{2}}$ & $\mathbf{j}_{\mathbf{3}}$ & $\mathbf{j}_{\mathbf{4}}$ \\
\hline $\mathbf{i}_{\mathbf{1}}$ & 2682 & 4839 & 858 & 705 \\
$\mathbf{i}_{\mathbf{2}}$ & 2313 & 3942 & 523 & 704 \\
$\mathbf{i}_{\mathbf{3}}$ & 1509 & 4077 & 229 & 694 \\
$\mathbf{i}_{\mathbf{4}}$ & 1211 & 4418 & 671 & 512 \\
$\mathbf{i}_{\mathbf{5}}$ & 1263 & 5210 & 366 & 487 \\
\hline
\end{tabular}

Each product has different volume. In Table 2, volume of products is shown:

Table 2 Volume that is occupied of products

\begin{tabular}{cccc}
\hline $\mathbf{j}_{\mathbf{1}}$ & $\mathbf{j}_{\mathbf{2}}$ & $\mathbf{j}_{\mathbf{3}}$ & $\mathbf{j}_{\mathbf{4}}$ \\
\hline 0,002 & 0,002 & 0,001 & 0,002 \\
\hline
\end{tabular}

The number of customer that comes to each brokers are different. The numbers of customers are shown in Table 3.

Table 3 Number of customer that comes to brokers

\begin{tabular}{ccccc}
\hline $\mathbf{i}_{\mathbf{1}}$ & $\mathbf{i}_{\mathbf{2}}$ & $\mathbf{i}_{\mathbf{3}}$ & $\mathbf{i}_{\mathbf{4}}$ & $\mathbf{i}_{\mathbf{5}}$ \\
\hline 43 & 32 & 41 & 32 & 39 \\
\hline
\end{tabular}

\subsection{Linear programming model}

In first step, the linear programming models are solved for exhibition area and two different layouts of warehouse using data. The assignment of brokers to exhibition areas and the assignment amounts of products for each broker can be found as follows in Table 4:

Table 4 Assignment of exhibition areas

\begin{tabular}{cccccc}
\hline $\begin{array}{c}\text { Broker/ } \\
\text { Exhibition Area }\end{array}$ & $\mathbf{l}_{\mathbf{1}}$ & $\mathbf{l}_{\mathbf{2}}$ & $\mathbf{l}_{\mathbf{3}}$ & $\mathbf{l}_{\mathbf{4}}$ & $\mathbf{l}_{\mathbf{5}}$ \\
\hline $\mathbf{i}_{\mathbf{1}}$ & & & 1 & & \\
$\mathbf{i}_{\mathbf{2}}$ & 1 & & & & \\
$\mathbf{i}_{3}$ & & 1 & & & \\
$\mathbf{i}_{\mathbf{4}}$ & & & & 1 & \\
$\mathbf{i}_{\mathbf{5}}$ & & & & & 1 \\
\hline
\end{tabular}

In Table 5, assignment of the brokers and amount of the products to the warehouse areas are shown for the broker based warehouse design.

Table $5 \mathrm{~A}_{21}$ Broker based warehouse design

\begin{tabular}{|c|c|c|c|c|c|c|}
\hline Broker & $\begin{array}{l}\text { Product } \\
\text { Type/ } \\
\text { Warehouse }\end{array}$ & $\mathbf{k}_{1}$ & $\mathbf{k}_{\mathbf{2}}$ & $\mathbf{k}_{4}$ & $\mathbf{k}_{6}$ & $\mathbf{k}_{7}$ \\
\hline $\mathbf{i}_{1}$ & $\mathbf{j}_{1}$ & & & & & 268 \\
\hline $\mathbf{i}_{1}$ & $\mathbf{j}_{2}$ & & & & & 483 \\
\hline $\mathbf{i}_{1}$ & $\mathbf{j}_{3}$ & & & & & 858 \\
\hline $\mathbf{i}_{1}$ & $\mathbf{j}_{4}$ & & & & & 705 \\
\hline $\mathbf{i}_{2}$ & $\mathbf{j}_{1}$ & 231 & & & & \\
\hline $\mathbf{i}_{2}$ & $\mathbf{j}_{2}$ & 394 & & & & \\
\hline $\mathbf{i}_{2}$ & $\mathbf{j}_{3}$ & 523 & & & & \\
\hline $\mathbf{i}_{2}$ & $\mathbf{j}_{4}$ & 704 & & & & \\
\hline $\mathbf{i}_{3}$ & $\mathbf{j}_{\mathbf{1}}$ & & & 150 & & \\
\hline $\mathbf{i}_{3}$ & $\mathbf{j}_{2}$ & & & 407 & & \\
\hline $\mathbf{i}_{3}$ & $\mathbf{j}_{3}$ & & & 229 & & \\
\hline $\mathbf{i}_{3}$ & $\mathbf{j}_{4}$ & & & 694 & & \\
\hline $\mathbf{i}_{4}$ & $\mathbf{j}_{1}$ & & & & 121 & \\
\hline $\mathbf{i}_{4}$ & $\mathbf{j}_{2}$ & & & & 441 & \\
\hline $\mathbf{i}_{4}$ & $\mathbf{j}_{3}$ & & & & 671 & \\
\hline $\mathbf{i}_{4}$ & $\mathbf{j}_{4}$ & & & & 512 & \\
\hline $\mathbf{i}_{5}$ & $\mathbf{j}_{1}$ & & 126 & & & \\
\hline$i_{5}$ & $\mathbf{j}_{2}$ & & 521 & & & \\
\hline $\mathbf{i}_{5}$ & $\mathbf{j}_{3}$ & & 366 & & & \\
\hline $\mathbf{i}_{5}$ & $\mathbf{j}_{4}$ & & 487 & & & \\
\hline
\end{tabular}

In Table 6, the assignment of brokers and the amount of products to the warehouse areas are shown for the product based warehouse design. 
Table 6 A22 Product based warehouse design

\begin{tabular}{cccccc}
\hline Broker & $\begin{array}{l}\text { ProductType/ } \\
\text { Warehouse }\end{array}$ & $\mathbf{k}_{\mathbf{1}}$ & $\mathbf{k}_{\mathbf{2}}$ & $\mathbf{k}_{\mathbf{6}}$ & $\mathbf{k}_{7}$ \\
\hline $\mathbf{i}_{1}$ & $\mathbf{j}_{1}$ & & & 2682 & \\
$\mathbf{i}_{1}$ & $\mathbf{j}_{2}$ & & 4839 & & \\
$\mathbf{i}_{1}$ & $\mathbf{j}_{3}$ & 858 & & & \\
$\mathbf{i}_{1}$ & $\mathbf{j}_{4}$ & & & & 705 \\
$\mathbf{i}_{2}$ & $\mathbf{j}_{1}$ & & & 2313 & \\
$\mathbf{i}_{2}$ & $\mathbf{j}_{2}$ & & 3942 & & \\
$\mathbf{i}_{2}$ & $\mathbf{j}_{3}$ & 523 & & & \\
$\mathbf{i}_{2}$ & $\mathbf{j}_{4}$ & & & & 704 \\
$\mathbf{i}_{3}$ & $\mathbf{j}_{1}$ & & & 1509 & \\
$\mathbf{i}_{3}$ & $\mathbf{j}_{2}$ & & 4077 & & \\
$\mathbf{i}_{3}$ & $\mathbf{j}_{3}$ & 229 & & & \\
$\mathbf{i}_{3}$ & $\mathbf{j}_{4}$ & & & & 694 \\
$\mathbf{i}_{4}$ & $\mathbf{j}_{1}$ & & & 1211 & \\
$\mathbf{i}_{4}$ & $\mathbf{j}_{2}$ & & 4418 & & \\
$\mathbf{i}_{4}$ & $\mathbf{j}_{3}$ & 671 & & & \\
$\mathbf{i}_{4}$ & $\mathbf{j}_{4}$ & & & & 512 \\
$\mathbf{i}_{5}$ & $\mathbf{j}_{1}$ & & & 1263 & \\
$\mathbf{i}_{5}$ & $\mathbf{j}_{2}$ & & 5210 & & \\
$\mathbf{i}_{5}$ & $\mathbf{j}_{3}$ & 366 & & & \\
$\mathbf{i}_{5}$ & $\mathbf{j}_{4}$ & & & & 487 \\
\hline
\end{tabular}

As a result of the calculating, minimum duration of rounding of large and small vehicles in hall are given as follows in Table 7:

Table 7 Total time for each layout

\begin{tabular}{lc}
\hline & Minutes \\
\hline Exhibition Area & 161,63 \\
Broker Based & 179,17 \\
Product Based & 173,94 \\
\hline
\end{tabular}

In second step, the problem is solved using real world data for 220 brokers and 260 warehouses. The total navigation time for the exhibition areas and the total loading and unloading times of products for the broker based and product based warehouse design are shown as follows in Table 8:

Table 8 Total time for each layout using real world data

\begin{tabular}{cc}
\hline & Minutes \\
\hline Exhibition Area & 23968,09 \\
Broker Based & 20026,27 \\
Product Based & 14715,40 \\
\hline
\end{tabular}

After comparing of the results, the most appropriate layout is determined as Product Based Warehouse Design for both small and large (real world) data.

\subsection{Possibilistic Linear Programming Model}

It is decided that the loading and unloading points of products, counts of customers and routing of customers in exhibition area are fuzzy. Therefore PLP is used for solving the problem.

Table 9 includes fuzzy data of the products which comes to the brokers. In this study, LP model is remodeled as a single goal using Zimmermann's 18 fuzzy programming method. When the model is converted, in first phase, PIS and NIS of objective functions is calculated and then the linear membership function of these functions can be computed.

Table 9 Amount of products which comes to brokers

\begin{tabular}{|c|c|c|c|c|c|}
\hline $\mathbf{m}^{\mathbf{0}}$ & $\begin{array}{r}\text { Broker/Product } \\
\text { Type }\end{array}$ & $\mathbf{j}_{1}$ & $\mathbf{j}_{2}$ & $\mathbf{j}_{3}$ & $\mathbf{j}_{4}$ \\
\hline & $\mathbf{i}_{1}$ & 18 & 1406 & 11 & 85 \\
\hline & $\mathbf{i}_{2}$ & 286 & 1477 & 11 & 99 \\
\hline & $\mathbf{i}_{3}$ & 384 & 1078 & 7 & 256 \\
\hline & $\mathbf{i}_{4}$ & 103 & 794 & 8 & 29 \\
\hline & $\mathbf{i}_{5}$ & 327 & 1647 & 8 & 124 \\
\hline \multirow[t]{6}{*}{$\mathbf{m}^{\mathbf{m}}$} & & $\mathbf{j}_{1}$ & $\mathbf{j}_{2}$ & $\mathbf{j}_{3}$ & $\mathbf{j}_{4}$ \\
\hline & $\mathbf{i}_{1}$ & 2682 & 4839 & 858 & 705 \\
\hline & $\mathbf{i}_{2}$ & 2313 & 3942 & 523 & 704 \\
\hline & $\mathbf{i}_{3}$ & 1509 & 4077 & 229 & 694 \\
\hline & $\mathbf{i}_{4}$ & 1211 & 4418 & 671 & 512 \\
\hline & $\mathbf{i}_{5}$ & 1263 & 5210 & 366 & 487 \\
\hline \multirow[t]{6}{*}{$\mathbf{m}^{\mathbf{p}}$} & & $\mathbf{j}_{1}$ & $\mathbf{j}_{2}$ & $\mathbf{j}_{3}$ & $\mathbf{j}_{4}$ \\
\hline & $\mathbf{i}_{1}$ & 5501 & 8930 & 2318 & 792 \\
\hline & $\mathbf{i}_{2}$ & 7869 & 5365 & 2218 & 947 \\
\hline & $\mathbf{i}_{3}$ & 7243 & 7592 & 4152 & 969 \\
\hline & $\mathbf{i}_{4}$ & 7666 & 5646 & 3300 & 903 \\
\hline & $i_{5}$ & 7831 & 7222 & 2709 & 754 \\
\hline
\end{tabular}

Table 10 includes the distances from parking points to the warehouses for the large and small vehicle used for loading of products. 
Table 10 Parking points of large and small vehicle for loading of product

\begin{tabular}{lllllllllll}
\hline $\begin{array}{l}\text { Distances } \\
\text { Warehouses }\end{array}$ & $\mathbf{k}_{\mathbf{1}}$ & $\mathbf{k}_{\mathbf{2}}$ & $\mathbf{k}_{\mathbf{3}}$ & $\mathbf{k}_{\mathbf{4}}$ & $\mathbf{k}_{\mathbf{5}}$ & $\mathbf{k}_{\mathbf{6}}$ & $\mathbf{k}_{\mathbf{7}}$ & $\mathbf{k}_{\mathbf{8}}$ & $\mathbf{k}_{\mathbf{9}}$ & $\mathbf{k}_{\mathbf{1 0}}$ \\
\hline $\mathbf{d b}^{\mathbf{0}}$ & 12,5 & 22,5 & 12,5 & 22,5 & 32,5 & 12,5 & 22,5 & 12,5 & 22,5 & 32,5 \\
$\mathbf{d b}^{\mathbf{m}}$ & 15 & 25 & 20 & 30 & 40 & 15 & 25 & 20 & 30 & 40 \\
$\mathbf{d b}^{\mathbf{p}}$ & 23,5 & 33,5 & 23,5 & 33,5 & 43,5 & 23,5 & 33,5 & 23,5 & 33,5 & 43,5 \\
\hline
\end{tabular}

Table 11 includes the distances from parking points to the warehouses for the large and small vehicle used for unloading of products.

Table 11 Parking points of large and small vehicle for unloading of product

\begin{tabular}{lrrrrrrrrrr}
\hline $\begin{array}{l}\text { Distances } \\
\text { /Warehouses }\end{array}$ & \multicolumn{1}{c}{$\mathbf{k}_{\mathbf{1}}$} & \multicolumn{1}{c}{$\mathbf{k}_{\mathbf{2}}$} & \multicolumn{1}{c}{$\mathbf{k}_{\mathbf{3}}$} & \multicolumn{1}{c}{$\mathbf{k}_{\mathbf{4}}$} & \multicolumn{1}{c}{$\mathbf{k}_{\mathbf{5}}$} & $\mathbf{k}_{\mathbf{6}}$ & \multicolumn{1}{c}{$\mathbf{k}_{\mathbf{7}}$} & $\mathbf{k}_{\mathbf{8}}$ & $\mathbf{k}_{\mathbf{9}}$ & $\mathbf{k}_{\mathbf{1 0}}$ \\
\hline $\mathbf{d y}^{\mathbf{0}}$ & 59,5 & 49,5 & 69,5 & 59,5 & 49,5 & 59,5 & 49,5 & 69,5 & 59,5 & 49,5 \\
$\mathbf{d y}^{\mathbf{m}}$ & 69 & 59 & 79 & 69 & 59 & 69 & 59 & 79 & 69 & 59 \\
$\mathbf{d y}^{\mathbf{p}}$ & 100 & 90 & 110 & 100 & 90 & 100 & 90 & 110 & 100 & 90 \\
\hline
\end{tabular}

\section{Solving Algorithm}

- Convert imprecise objective functions to the new crisp objective functions using Eq 14, Eq 15 and $\mathrm{Eq}$ 16 for exhibition area design; Eq 29, Eq 30, Eq 31 for broker based warehouse design; $\mathrm{Eq} \mathrm{47,} \mathrm{Eq} \mathrm{48,}$ Eq 49 for product based warehouse design.

- Convert imprecise constraints to the new crisp constraints using Eq 17, Eq 18 for exhibition area design; Eq 32, Eq 33, Eq 34, Eq 35, Eq 36, Eq 37 for broker based warehouse design; Eq 50, Eq 51, Eq 52, Eq 53, Eq 54 and Eq 55 for product based warehouse design.

- Solve the multi-objective crisp objective functions with the crisp constraints.

- Calculate PIS and NIS using GAMS progrramming.

- Calculate the membership functions of the auxiliary objective functions.

- Construct the single-objective model with the aid of the membership functions and calculate the optimum satisfaction degree $\lambda$.

At first, PIS and NIS values are computed for each layout using small data. The results of PIS and NIS values of $\mathrm{A} 1$ is shown at Table 12.

Table 12 PIS and NIS values of $A_{1}$

\begin{tabular}{rrr}
\hline & \multicolumn{1}{c}{ PIS } & \multicolumn{1}{c}{ NIS } \\
\hline $\mathbf{z}_{1}$ & 169,71 & 161,63 \\
$\mathbf{z}_{\mathbf{2}}$ & 13,57 & 18,77 \\
$\mathbf{z}_{3}$ & 129,69 & 124,44 \\
\hline
\end{tabular}

The objective function and new constraint for A1 are shown as follows:

$\max \lambda^{(1)}$

$\lambda^{(1)} \leq \frac{z_{1}(x) \quad 169,71}{169,71 \quad 161,63}$

$$
\begin{aligned}
\lambda^{(1)} & \leq \frac{13,57 \quad z_{2}(x)}{13,57 \quad 18,77} \\
\lambda^{(1)} & \leq \frac{z_{3}(x) \quad 129,69}{124,44 \quad 129,69}
\end{aligned}
$$

Total time for A1 is calculated as $(164,23 ; 7,37 ; 125,93)$ minute and the satisfied value for the A1 is 0,71 . The assignments of brokers to the exhibition areas for exhibition area design are shown at Table 13.

Table 13 The assignment of $A_{1}$ using PLP

\begin{tabular}{cccccc}
\hline Brokers/ Exhibition Area & $\mathbf{l}_{\mathbf{1}}$ & $\mathbf{l}_{\mathbf{2}}$ & $\mathbf{l}_{\mathbf{3}}$ & $\mathbf{l}_{\mathbf{4}}$ & $\mathbf{l}_{\mathbf{5}}$ \\
\hline $\mathbf{i}_{\mathbf{1}}$ & & & 1 & & \\
$\mathbf{i}_{\mathbf{2}}$ & & & & & 1 \\
$\mathbf{i}_{3}$ & & 1 & & & \\
$\mathbf{i}_{\mathbf{4}}$ & & & & 1 & \\
$\mathbf{i}_{\mathbf{5}}$ & 1 & & & \\
\hline
\end{tabular}

Second PIS and NIS values are computed for broker based warehouse design $\left(A_{21}\right)$. They are shown in Table 14.

Table 14 The PIS and NIS values for the assignment of brokers $\mathrm{A}_{21}$

\begin{tabular}{lrr}
\hline & \multicolumn{1}{c}{ PIS } & \multicolumn{1}{c}{ NIS } \\
\hline $\mathbf{z}_{\mathbf{1}}$ & \multicolumn{1}{c}{239,11} & 209,71 \\
$\mathbf{z}_{\mathbf{2}}$ & 31,26 & 41,06 \\
$\mathbf{z}_{\mathbf{3}}$ & 93,12 & 83,32 \\
\hline
\end{tabular}

The objective function and new constraint for A21 are shown as follows:

$\max \lambda^{(1)}$

$$
\begin{aligned}
\lambda^{(1)} & \leq \frac{z_{1}(x)}{209,71} 239,11 \\
\lambda^{(1)} & \leq \frac{31,26 \quad z_{2}(x)}{31,26 \quad 41,06} \\
\lambda^{(1)} & \leq \frac{z_{3}(x)}{83,32} 993,12
\end{aligned}
$$


Then total time for A21 is calculated as $(223,80 ; 35,96$; $88,43)$ minute and the satisfied value for the A21 is 0,48 . The assignments of brokers and products to the wholesalers for broker based warehouse design are shown in Table 15.

Table 15 The assignment of $\mathrm{A}_{21}$ using PLP

\begin{tabular}{|c|c|c|c|c|c|c|}
\hline Brokers & $\begin{array}{l}\text { Product Type / } \\
\text { Wholesalers } \\
\end{array}$ & $\mathbf{k}_{1}$ & $\mathbf{k}_{3}$ & $\mathbf{k}_{4}$ & $k_{6}$ & $\mathbf{k}_{8}$ \\
\hline $\mathbf{i}_{1}$ & $\mathbf{j}_{1}$ & & & & 2707,83 & \\
\hline$i_{1}$ & $\mathbf{j}_{2}$ & & & & 4948,67 & \\
\hline $\mathbf{i}_{1}$ & $\mathbf{j}_{3}$ & & & & 960,17 & \\
\hline $\mathbf{i}_{1}$ & $\mathbf{j}_{4}$ & & & & 616,17 & \\
\hline $\mathbf{i}_{2}$ & $\mathbf{j}_{1}$ & 2901,17 & & & & \\
\hline $\mathbf{i}_{2}$ & $\mathbf{j}_{2}$ & 3768,33 & & & & \\
\hline $\mathbf{i}_{2}$ & $\mathbf{j}_{3}$ & 720,17 & & & & \\
\hline $\mathbf{i}_{2}$ & $\mathrm{j}_{4}$ & 643,67 & & & & \\
\hline $\mathbf{i}_{3}$ & $\mathbf{j}_{1}$ & & & 2277,17 & & \\
\hline $\mathbf{i}_{3}$ & $\mathbf{j}_{2}$ & & & 4163,00 & & \\
\hline $\mathbf{i}_{3}$ & $\mathbf{j}_{3}$ & & & 845,83 & & \\
\hline $\mathbf{i}_{3}$ & $\mathbf{j}_{4}$ & & & 666,83 & & \\
\hline $\mathbf{i}_{4}$ & $\mathbf{j}_{1}$ & & & & & 2102,17 \\
\hline $\mathbf{i}_{4}$ & $\mathbf{j}_{2}$ & & & & & 4018,67 \\
\hline $\mathbf{i}_{4}$ & $\mathbf{j}_{3}$ & & & & & 998,67 \\
\hline $\mathbf{i}_{4}$ & $\mathbf{j}_{4}$ & & & & & 496,67 \\
\hline$i_{5}$ & $\mathbf{j}_{1}$ & & 2201,67 & & & \\
\hline $\mathbf{i}_{5}$ & $\mathbf{j}_{2}$ & & 4951,50 & & & \\
\hline$i_{5}$ & $\mathbf{j}_{3}$ & & 696,83 & & & \\
\hline$i_{5}$ & $\mathrm{j}_{4}$ & & 471,00 & & & \\
\hline
\end{tabular}

After the calculation of $\mathrm{A}_{21}$, PIS and NIS values are computed for product based warehouse design $\left(A_{22}\right)$. The results are shown in Table 16.

Table 16 The PIS and NIS values for the assignment of products $\mathrm{A}_{22}$

\begin{tabular}{lrr}
\hline & PIS & NIS \\
\hline $\mathbf{z}_{\mathbf{1}}$ & 239,11 & 202,88 \\
$\mathbf{z}_{\mathbf{2}}$ & 28,98 & 41,06 \\
$\mathbf{z}_{\mathbf{3}}$ & 95,40 & 83,32 \\
\hline
\end{tabular}

The objective function and new constraint for $\mathrm{A}_{22}$ are shown as follows:

$$
\begin{aligned}
& \max \lambda^{(1)} \\
& \lambda^{(1)} \leq \frac{z_{1}(x) \quad 239,11}{202,88 \quad 239,11}
\end{aligned}
$$

$$
\begin{aligned}
& \lambda^{(1)} \leq \frac{28,98 \quad z_{2}(x)}{28,98 \quad 41,06} \\
& \lambda^{(1)} \leq \frac{z_{3}(x) \quad 95,4}{83,32 \quad 95,4}
\end{aligned}
$$

The assignments of brokers and products to the

\begin{tabular}{|c|c|c|c|c|c|}
\hline Brokers & $\begin{array}{l}\text { Product Type / } \\
\text { Wholesalers }\end{array}$ & $\mathbf{k}_{1}$ & $\mathbf{k}_{2}$ & $\mathbf{k}_{3}$ & $\mathbf{k}_{4}$ \\
\hline $\mathbf{i}_{1}$ & $\mathbf{j}_{1}$ & & & & 2707,83 \\
\hline $\mathbf{i}_{1}$ & $\mathbf{j}_{2}$ & & 4948,67 & & \\
\hline $\mathbf{i}_{1}$ & $\mathbf{j}_{3}$ & & & 960,17 & \\
\hline $\mathbf{i}_{1}$ & $\mathrm{j}_{4}$ & 616,17 & & & \\
\hline $\mathbf{i}_{2}$ & $\mathbf{j}_{1}$ & & & & 2901,17 \\
\hline $\mathbf{i}_{2}$ & $\mathbf{j}_{2}$ & & 3768,33 & & \\
\hline $\mathbf{i}_{2}$ & $\mathbf{j}_{3}$ & & & 720,17 & \\
\hline $\mathbf{i}_{2}$ & $\mathrm{j}_{4}$ & 643,67 & & & \\
\hline $\mathbf{i}_{3}$ & $\mathbf{j}_{1}$ & & & & 2277,17 \\
\hline $\mathbf{i}_{3}$ & $\mathbf{j}_{2}$ & & 4163,00 & & \\
\hline $\mathbf{i}_{3}$ & $\mathbf{j}_{3}$ & & & 845,83 & \\
\hline $\mathbf{i}_{3}$ & $\mathbf{j}_{4}$ & 666,83 & & & \\
\hline $\mathbf{i}_{4}$ & $\mathbf{j}_{1}$ & & & & 2102,17 \\
\hline $\mathbf{i}_{4}$ & $\mathbf{j}_{2}$ & & 4018,67 & & \\
\hline $\mathbf{i}_{4}$ & $\mathbf{j}_{3}$ & & & 998,67 & \\
\hline $\mathbf{i}_{4}$ & $\mathbf{j}_{4}$ & 496,6667 & & & \\
\hline $\mathbf{i}_{5}$ & $\mathbf{j}_{1}$ & & & & 2201,67 \\
\hline $\mathbf{i}_{5}$ & $\mathbf{j}_{2}$ & & 4951,5 & & \\
\hline $\mathbf{i}_{5}$ & $\mathbf{j}_{3}$ & & & 696,83 & \\
\hline $\mathbf{i}_{5}$ & $\mathrm{j}_{4}$ & 471 & & & \\
\hline
\end{tabular}
wholesalers for product based warehouse design are shown in Table 17.

Table 17 The assignment of A22 using PLP

Then total time for $\mathrm{A}_{22}$ is calculated as $(222,04 ; 35,37$; $89,01)$ minute and the satisfied value for the $A_{22}$ is 0,51 . The results are shown in Table 18.

Table 18 The Total times for $A_{1}, A_{21}, A_{22}$ using small data

\begin{tabular}{lcrrc}
\hline Layout type & $\mathbf{z}_{\mathbf{1}}$ & $\mathbf{z}_{\mathbf{2}}$ & \multicolumn{1}{c}{$\mathbf{z}_{\mathbf{3}}$} & $\lambda^{1}$ \\
\hline $\mathrm{A}_{1}$ & 164,23 & 17,37 & 125,93 & 0,68 \\
$\mathrm{~A}_{21}$ & 223,80 & 35,96 & 88,43 & 0,48 \\
$\mathrm{~A}_{22}$ & 222,04 & 35,37 & 89,01 & 0,47 \\
\hline
\end{tabular}


In second step, the models are calculed using real world values. The used data in the case study is shown follows: number of brokers are 220, number of warehouse 260 and capacity of each warehouse is 595 $\mathrm{m} 3$.

The model is calculated using real world values and the results is shown as follows in Table 19.

Table 19 The Total times for $\mathrm{A}_{1}, \mathrm{~A}_{21}, \mathrm{~A}_{22}$ using real world data

\begin{tabular}{lcccc}
\hline Layout type & $\mathbf{z}_{\mathbf{1}}$ & $\mathbf{z}_{\mathbf{2}}$ & $\mathbf{z}_{\mathbf{3}}$ & $\lambda^{1}$ \\
\hline $\mathrm{A}_{1}$ & 25631,30 & 1181,34 & 28714,90 & 1,00 \\
$\mathrm{~A}_{21}$ & 24818,31 & 1266,92 & 14732,07 & 0,52 \\
$\mathrm{~A}_{22}$ & 22271,08 & 1059,96 & 14123,47 & 0,54 \\
\hline
\end{tabular}

The results show us that most appropriate layout is selected as $\mathrm{A}_{22}$ with minimum total time and 0,54 satisfied values.

\section{Conclusions}

In this study, it is aimed to find the most appropriate assignment of products/brokers to warehouse and exhibition areas for developing a decision making system on urban distribution center layout. The main objective is to minimize the total walking and driving distances in the market hall. The exhibition area layout and two different warehouse area layouts are optimized together in the study. The models were developed for two different wholesale market hall layouts using LP and PLP methodologies. The same data was used to solve LP and PLP models using GAMS programming. There are no big differences between A21 and A22 considering the total time for small sized data. A22 layout which has min total time is decided as most appropriate layout for PLP model using small sized data and LP model using real world data.

When this study is compared with other studies in literature, superiorities of the proposed models are as follows:

- In the previous studies related to the distribution center, layout areas are not examined by dividing them into two types as exhibition and warehouse areas. In this study, these two problems have been solved in an integrated way. (the proposed models of integrating these two problems are solved in a way)
- We have not found any study about "according to product placement" for the fruits and vegetable halls layout in literature. In this study, we proposed a new layout design for the fruits and vegetables halls as the product based warehouse design. In additon to this, we compared two different layout designs (product based and broker based) and proposed the most appropriate alternative for the fruits and vegetables halls.

- In the proposed models, if total amount of products that comes to the broker, exceeds store capacity in warehouse area reserved for the broker, the products are assigned to the warehouse areas according to store capacity, respectively. According to the constraint, product quantities that exceed the capacity of the store is assigned to a different store.

In future studies, the number of the brokers, the products and the vehicle types may be increased. Since the product types are affected from the seasonal changes, this factor may be included in the model and two different layouts may be offered for the two terms of the year. On the other hand, layout decisions may change according to the location. Therefore, layout and location selection problems may be modelled integratedly. And alternative layout types in different locations around the city may be compared concurrently.

\section{References}

1. Demirtas, N., Tuzkaya, U.,R., 2012, Strategic planning of layout of the distribution center: an approach for fruits and vegetables hall, Procedia - Social and Behavioral Sciences 58, $159-168$

2. Chen, M., C., Huang,C.,L., Chen,K.,Y., ,Wud, H.,P, 2005, Aggregation of orders in distribution centers using data mining, Expert Systems with Applications, 28, 453460

3. Xing, M., Wang, Z., Cheng,G., Zhang, Q., 2011, Study on Location Adjustment Model of Store Area in Distribution Center Based on Shortest Picking Time, Procedia Engineering 24, 604- 609

4. Avittathur, B., Shah, J., Gupta, O., K., 2005, Distribution centre location modelling for differential sales tax structure, European Journal of Operational Research ,162, 191-205

5. Yang,L., Jib, X., Gaoa,Z., Lia, K., 2007, Logistics distribution centers location problem and algorithm under fuzzy environment, Journal of Computational and Applied Mathematics 208, 303 - 315

6. Tanyas., M., 2010, Meyve Sebze Lojistiği, International Logistics and Supply Chain Congress 
7. Tanyas, M., Tuzkaya, U.R., Alp, Ö.N., Demirtaş, N., Baraçl1, H., 2011, Distribution Center Layout Design Selection By Using Axiomatic Design: A Specific Case For Fruits And Vegetables Wholesale Market Hall, International Logistics and Supply Chain Congress' 2011

8. Assadipour, G., Razmi, J., 2013, Possibilistic inventory and supplier selection model for an assembly system, Int J Adv Manuf Technol, 67,575-587

9. Vahdani, B., Dehbari, S., Naderi-Beni, M.,Kh, E.,Z., 2014, An artificial intelligence approach for fuzzy possibilistic-stochastic multi-objective logistics network design, The Natural Computing Applications Forum 25,1887-1902

10. Bouzembrak, Y., Allaouı, H., Goncalves, G., Bouchriha, H., Baklout1, M., 2013, A possibilistic linear programming model for supply chain network design under uncertainty, IMA Journal of Management Mathematics, 24,209-229

11. Ozgen, D., Gulsun, B.,2014, Combining possibilistic linear programming and fuzzy AHP for solving the multiobjective capacitated multi-facility location problem, Information Sciences 268, 185-201

12. Niakan, F, Rahimi, M.,2015, A multi-objective healthcare inventory routing problem; a fuzzy possibilistic approach,Transportation Research 80,74-94
13. Tofighi, S., Torabi, S.,A., Mansouri, S.,A.,2016, Humanitarian logistics network design under mixed uncertainty,European Journal of Operational Research 250, 239-250

14. Dai, C., Cai, Y.,P., Ren, W., Xie, Y.,F., Guo, H.,C.,2016, Identification of optimal placements of best management practicesthrough an interval-fuzzy possibilistic programming model, Agricultural Water Management, 165,108-121

15. Zadeh, L.A., 2005, "A Generalized Theory of Uncertainty (GTU) - An Outline”, Information Sciences, $172,1-40$.

16. Ozgen, D., Onut, S., Gulsun, B., Tuzkaya, U.R., Tuzkaya, G., 2008, A Two-Phase Possibilistic Linear Programming Methodology For Multi-Objective Supplier Evaluation And Order Allocation Problems, Information Sciences, 178, 485-500

17. Lai,Y. ve Hwang,C., 1992, A New Approach to Some Possibilistic Linear Programming Problems, Fuzzy Sets and Systems, 49, 121-133.

18. Zimmermann, H.J., 1978, "Fuzzy Programming and Linear Programming with Several Objective Functions", Fuzzy sets and Systems, 1,45-55. 